\title{
The Effect Of Ramp Rate On The C49 To C54 Titanium Disilicide Phase Transformation From Ti And Ti(Ta)
}

\author{
Paul Martin Smith and Glenn Bailey \\ Sandia National Laboratories, Albuquerque, NM 87185-1084 \\ Yao Zhi Hu and Sing Pin Tay \\ Steag RTP Systems Inc., 4425 Fortran Dr., San Jose, CA 95134
}

The $\mathrm{C} 49$ to $\mathrm{C} 54 \mathrm{TiSi}_{2}$ transformation temperature is shown to be reduced by increasing the ramp rate during rapid thermal processing and this effect is more pronounced for thinner initial $\mathrm{Ti}$ and $\mathrm{Ti}(\mathrm{Ta})$ films. Experiments were performed on blanket wafers and on wafers that had patterned polycrystalline $\mathrm{Si}$ lines with $\mathrm{Si}_{3} \mathrm{~N}_{4}$ sidewall spacers. Changing the ramp rate caused no change in the transformation temperature for $60 \mathrm{~nm}$ blanket Ti films. For blanket Ti films of 25 or $40 \mathrm{~nm}$, however, increasing the ramp rate from 7 to $180^{\circ} \mathrm{C} / \mathrm{s}$ decreased the transformation temperature by $15^{\circ} \mathrm{C}$. Studies of patterned lines indicate that sheet resistance of narrow lines is reduced by increased ramp rates for both $\mathrm{Ti}$ and $\mathrm{Ti}(\mathrm{Ta})$ films, especially as the linewidths decrease below $0.4 \mu \mathrm{m}$. This improvement is particularly pronounced for the thinnest $\mathrm{Ti}(\mathrm{Ta})$ films, which exhibited almost no linewidth effect after being annealed with a ramp rate of $75^{\circ} \mathrm{C} / \mathrm{s}$. 


\section{DISCLAIMER}

This report was prepared as an account of work sponsored by an agency of the United States Government. Neither the United States Government nor any agency thereof, nor any of their employees, make any warranty, express or implied, or assumes any legal liability or responsibility for the accuracy, completeness, or usefulness of any information, apparatus, product, or process disclosed, or represents that its use would not infringe privately owned rights. Reference herein to any specific commercial product, process, or service by trade name, trademark, manufacturer, or otherwise does not necessarily constitute or imply its endorsement, recommendation, or favoring by the United States Government or any agency thereof. The views and opinions of authors expressed herein do not necessarily state or reflect those of the United States Government or any agency thereof. 


\section{DISCLAIMER}

Portions of this document may be illegible in electronic image products. Images are produced from the best available original document. 


\section{Introduction}

Self-aligned titanium silicide (Ti-salicide) has been used for many generations of ULSI devices because of its temperature stability and low resistivity. ${ }^{1,2}$ Unfortunately, reliably producing low resistivity $\mathrm{TiSi}_{2}$ on lines narrower than $\approx 0.3 \mu \mathrm{m}$ is difficult. ${ }^{1,3-5}$ If Tisalicide is to remain a viable technology for ULSI applications, techniques must be found that overcome this difficulty. Toward that end, we show that the ramp rate used for Tisalicide processing is an important parameter for controlling this linewidth effect.

Titanium disilicide is a polymorphic material that may exist as the C49 phase or as the thermodynamically favored $\mathrm{C} 54$ phase. $^{6}$ During annealing of thin Ti films in contact with Si the first $\mathrm{TiSi}_{2}$ phase to form is $\mathrm{C} 49$, which forms above $500^{\circ} \mathrm{C}$, is metastable, and has a high resistivity $\left(40-90 \mu \Omega\right.$-cm). Upon continued heating to over $700^{\circ} \mathrm{C}$ the $\mathrm{C} 49$ transforms to $\mathrm{C} 54$, which is stable and has a low resistivity $(15-20 \mu \Omega-\mathrm{cm}){ }^{2,4,6,7}$ The activation energy for this transformation is $\geq 3.7 \mathrm{eV}$. $^{6-8}$

Typical Ti-salicide processing ${ }^{2,9}$ consists of depositing a Ti film on a patterned wafer with regions of exposed $\mathrm{Si}$ in a field of dielectric material, typically $\mathrm{SiO}_{2}$ or $\mathrm{Si}_{3} \mathrm{~N}_{4}$. A rapid thermal process (RTP) is performed at a relatively low temperature, about $700^{\circ} \mathrm{C}$, to react the $\mathrm{Ti}$ and exposed $\mathrm{Si}$ to form $\mathrm{C} 49 \mathrm{TiSi}_{2}$ while the remaining $\mathrm{Ti}$ is unreacted. This $\mathrm{RTP}$ is done in a $\mathrm{N}_{2}$ ambient, which creates a thin TiN layer over the entire wafer. The low RTP temperature and TiN prevent bridging, or electrical shorting, by reducing lateral $\mathrm{Si}$ diffusion. $^{2}$ A wet etch is then used to selectively remove only the TiN and unreacted Ti. A second RTP is performed at a relatively high temperature, about $850^{\circ} \mathrm{C}$, to transform the C49 into the desired C54 $\mathrm{TiSi}_{2}$ phase. Thermal budget issues and TiSi2 agglomeration ${ }^{2,3}$ limit the temperature of this RTP.

Previous work has shown the C54 $\mathrm{TiSi}_{2}$ phase selectively nucleates in thin films of C49 $\mathrm{TiSi}_{2}$ at a grain edge (where three grains meet). ${ }^{10}$ Once the linewidth shrinks below the size of an average $\mathrm{C} 49$ grain (i.e., bamboo structure) grain edges are rare and nucleation of the $\mathrm{C} 54$ phase is significantly reduced. ${ }^{1}$ This problem is further aggravated by the fact that typical Ti-salicide thicknesses are also decreasing and the problem is actually caused by the limited volume of $\mathrm{TiSi}_{2}$ material being transformed. In order to extend Ti-salicide manufacturing to deep submicron applications there have been many studies of the C49 to C54 transformation. ${ }^{3-16}$ The transformation temperature has been shown to be a function of film thickness, ${ }^{6,17} \mathrm{C} 49$ grain size, ${ }^{12}$ dopants in the $\mathrm{Si}^{3}{ }^{3}$ and other factors. The transformation temperature is reduced by small quantities of refractory metal, such as Mo, $\mathrm{Ta}, \mathrm{Nb}$, or $\mathrm{W}$, introduced at or near the Ti/Si interface. ${ }^{5,711,13}$ Earlier work also showed the $\mathrm{C} 49$ grain size of blanket $\mathrm{Ti}$ films on $<100>\mathrm{Si}$ can be reduced, and the transformation 
temperature lowered, by increasing the ramp rate of the first RTP. ${ }^{12}$ More recent work showed that higher ramp rates result in lower sheet resistance for deep submicron lines. ${ }^{14}$ In this paper we report on varying the as-deposited $\mathrm{Ti}$ or $\mathrm{Ti}(\mathrm{Ta})$ film thicknesses and ramp rates during RTP of blanket films and patterned lines. The C49 to C54 transformation temperature is reduced by increasing the as-deposited film thickness and by increasing the RTP ramp rate.

\section{Experiment}

Blanket samples were prepared by sputtering nominally 25,40 , or $60 \mathrm{~nm}$ Ti films onto 300 $\mathrm{nm}$ of undoped polycrystalline $\mathrm{Si}$ (poly-Si). The poly-Si was deposited on a $12.5 \mathrm{~nm}$ grown oxide and these substrates were annealed at $600^{\circ} \mathrm{C}$ for 60 minutes and $900^{\circ} \mathrm{C}$ for 30 minutes to fully crystallize the poly-Si and reduce film stress prior to Ti deposition. All of the sputter depositions in this study, on both blanket and patterned samples, were performed with no sputter etch. RTP of the blanket samples was carried out at temperatures ranging from 300 to $1000^{\circ} \mathrm{C}$ with ramp rates of $7,30,70$, and $180^{\circ} \mathrm{C} / \mathrm{s}$. The sheet resistance of the as-deposited films and the silicided films were measured by fourpoint probe. Our definition of the transformation temperature, $\mathrm{T}_{\mathrm{TR}}$, follows Lin and Pramanik, ${ }^{15}$ and is defined as the temperature where a linear fit to the sheet resistance in the $\mathrm{C} 49$ to $\mathrm{C} 54$ transformation region intersects a linear fit to the sheet resistance in the C54 region.

Patterned samples of electrically isolated, Ti-salicided lines designed to maximize the linewidth effect were produced on $150 \mathrm{~mm} \mathrm{Si}<100>$ wafers. The processing started with a $12.5 \mathrm{~nm}$ grown thermal oxide followed by $300 \mathrm{~nm}$ of deposited poly-Si. The poly-Si was implanted with $8 \times 10^{15} \mathrm{As} / \mathrm{cm}^{2}$ at $120 \mathrm{keV}$, capped with $500 \mathrm{~nm}$ of deposited oxide, and annealed at $1100^{\circ} \mathrm{C}$ in $\mathrm{N}_{2}$ for 180 minutes to activate the implant and reduce film stress. The oxide was stripped and the poly-Si was patterned to linewidths of $0.27 \mu \mathrm{m}$ and greater, as measured by scanning electron microscopy (SEM) after the processing was complete. A $180 \mathrm{~nm} \mathrm{Si}_{3} \mathrm{~N}_{4}$ film was deposited on the samples and etched back to form sidewall spacers. The wafers were cleaned in 5:1 $\mathrm{H}_{2} \mathrm{SO}_{4}: \mathrm{H}_{2} \mathrm{O}_{2}$ for 5 minutes, SC-1 for 10 minutes, SC-2 for 5 minutes, and 30:1 BOE for 1 minute immediately prior to $\mathrm{Ti}$ or $\mathrm{Ti}(\mathrm{Ta})$ deposition. The nominally $40 \mathrm{~nm}$ Ti film was sputter deposited. The nominally 25 and $40 \mathrm{~nm}$ Ti(Ta) films were sputtered from a $\mathrm{Ti}(\mathrm{Ta})$ target that was produced by evaporating $300 \mathrm{~nm}$ of Ta onto the erosion zone of a pure Ti sputter target. The Ta was evaporated onto the Ti target through a patterned shield and the resulting $\mathrm{Ti}(\mathrm{Ta})$ target produced approximately $100 \mathrm{~nm}$ of sputtered $\mathrm{Ti}(\mathrm{Ta})$ material $(\approx 4$ at. $\% \mathrm{Ta}$ in $\mathrm{Ti})$ before all the $\mathrm{Ta}$ was eroded from the sputter target. Approximately $10 \mathrm{~nm}$ of material was deposited from the Ti(Ta) target onto 
a dummy wafer to clean the target and then the 25 and $40 \mathrm{~nm}$ of Ti(Ta) was deposited onto the patterned wafers. The composition of the Ti(Ta) was determined by Rutherford backscattering spectrometry (RBS) on a similarly produced film. The as-deposited sheet resistance of the films was $\approx 19 \Omega / \mathrm{sq}$. for the $40 \mathrm{~nm} \mathrm{Ti} \mathrm{film,} \approx 25 \Omega / \mathrm{sq}$. for the $40 \mathrm{~nm} \mathrm{Ti(Ta)}$ film, and $\approx 36 \Omega / \mathrm{sq}$. for the $25 \mathrm{~nm} \mathrm{Ti(Ta)} \mathrm{film.} \mathrm{The} \mathrm{patterned} \mathrm{wafers} \mathrm{were} \mathrm{diced} \mathrm{into}$ samples and annealed in an RTP system at $700^{\circ} \mathrm{C}$ for 20 seconds with ramp rates of 5,30 , and $75^{\circ} \mathrm{C} / \mathrm{s}$ for the Ti film and 30 and $75^{\circ} \mathrm{C} / \mathrm{s}$ for the Ti(Ta) films. The samples were then etched in SC-1 to remove any $\mathrm{TiN}$ and unreacted $\mathrm{Ti}$ and the samples were annealed at $850^{\circ} \mathrm{C}$ for 30 seconds with a ramp rate of $30^{\circ} \mathrm{C} / \mathrm{s}$.

\section{Results and Discussion}

\section{A. Blanket Ti Samples}

Figure 1 shows sheet resistance versus RTP temperature for the 25, 40, and $60 \mathrm{~nm}$ blanket Ti films annealed from 300 to $1000^{\circ} \mathrm{C}$ with a ramp rate of $70^{\circ} \mathrm{C} / \mathrm{s}$. There are three distinct transitions for all three thicknesses. The first transition, with increasing temperature, is a resistivity increase that occurs above $300^{\circ} \mathrm{C}$ and probably corresponds to the formation of a metal rich silicide. ${ }^{18}$ The second transition corresponds to the $\mathrm{C} 49$ formation and occurs by $620^{\circ} \mathrm{C}$ in all three cases. The gradual decrease in resistivity between the second and third transitions is probably due to grain coarsening of the $\mathrm{C} 49$ phase. The third transition corresponds to the transformation from $\mathrm{C} 49$ to $\mathrm{C} 54$ and always occurs within $\mathrm{a} \approx 30^{\circ} \mathrm{C}$ temperature window, although the window shifts higher in temperature as the Ti film thickness decreases. Once the third transition is complete, at temperature $T_{T R}$, the resistivity remains stable until agglomeration begins. Note that the thinnest Ti film has both the highest transformation temperature and the lowest agglomeration temperature. This provides a good illustration of why the Ti-salicide process window is narrowing as device geometries decrease.

Blanket samples with Ti thicknesses of 25,40 , and $60 \mathrm{~nm}$ were annealed for 20 seconds at temperatures from 620 to $840^{\circ} \mathrm{C}$ with ramp rates of 7,30 , and $180^{\circ} \mathrm{C} / \mathrm{s}$. Figure 2 shows the sheet resistances versus RTP temperatures for the 25 and $60 \mathrm{~nm}$ blanket Ti films. It is obvious that the transformation temperature of the $60 \mathrm{~nm}$ Ti film is not affected by increasing the ramp rate, while the transformation temperature of the $25 \mathrm{~nm}$ Ti film is monatonically reduced by increasing the ramp rate. The transformation temperatures, $\mathrm{T}_{\mathrm{TR}}$, for all the blanket films are plotted in Figure 3 as a function of nominal Ti film thicknesses. In all cases, the transformation temperature increased by at least $50^{\circ} \mathrm{C}$ as the thickness decreased from 60 to $25 \mathrm{~nm}$. Changing the ramp rate did not significantly affect $\mathrm{T}_{\mathrm{TR}}$. for the $60 \mathrm{~nm}$ Ti films. For the 40 and $25 \mathrm{~nm} \mathrm{Ti}$ films, however, $\mathrm{T}_{\mathrm{TR}}$ was reduced by $15^{\circ} \mathrm{C}$ as 
the ramp rate was increased from 7 to $180^{\circ} \mathrm{C}$. This clearly shows that increasing the ramp rate partially compensates for the increase in $\mathrm{T}_{\mathrm{TR}}$ that occurs as the film thickness decreases.

\section{B. Patterned Ti and Ti(Ta) Samples}

Figure 4 shows sheet resistance as a function of linewidth and ramp rate for the patterned samples with $40 \mathrm{~nm}$ Ti. Each data point is an average of two or four measurements and the error bars indicate the maximum and minimum data values. As expected, the sheet resistance increases as the lines narrow, indicating that the transformation is being inhibited by the volume reduction. With a ramp rate of $5^{\circ} \mathrm{C} / \mathrm{s}$ there is already a significant increase by $0.6 \mu \mathrm{m}$ and the sheet resistance increases by a factor of $\approx 2.4 \mathrm{x}$ at the minimum linewidth. As the ramp rate increases the linewidth effect progressively decreases. The sheet resistance increase observed for the sample with the $75^{\circ} \mathrm{C} / \mathrm{s}$ ramp rate was only $\approx 10 \%$ at $0.4 \mu \mathrm{m}$ and only a factor of $\approx 1.8 \mathrm{x}$ at the minimum linewidth of $0.27 \mu \mathrm{m}$.

For the $40 \mathrm{~nm} \operatorname{Ti}(\mathrm{Ta})$ film, there was no observed linewidth effect. Because this effect is clearly seen for the $40 \mathrm{~nm} \mathrm{Ti}$ film, the difference is attributed to the $\approx 4$ at.\% Ta in the film, which agrees with previously published findings. ${ }^{5,13}$ Figure 5 shows the sheet resistance as a function of linewidth and ramp rate for the patterned samples with $25 \mathrm{~nm}$ Ti(Ta) films. As in Figure 4, each data point is an average of two or four measurements and the error bars indicate the maximum and minimum data values. There is an obvious reduction in the linewidth effect due to the increased ramp rate. With a ramp rate of $30^{\circ} \mathrm{C} / \mathrm{s}$ there is an increase in sheet resistance at $0.7 \mu \mathrm{m}$ that continues to grow with decreasing linewidth until it has increased by a factor of $\approx 2.1 \mathrm{x}$ at the minimum linewidth. In sharp contrast, increasing the ramp rate to $75^{\circ} \mathrm{C} / \mathrm{s}$ has essentially eliminated the linewidth effect and there is only $\mathrm{a} \approx 10 \%$ increase in the sheet resistance even at the minimum linewidth.

\section{Conclusions}

This work has shown that the $\mathrm{C} 49$ to $\mathrm{C} 54 \mathrm{TiSi}_{2}$ transformation temperature is increased by reducing the initial $\mathrm{Ti}$ film thickness and reduced by increasing the RTP ramp rate. This effect was observed for $\mathrm{Ti}$ and $\mathrm{Ti}(\mathrm{Ta}$ ) films. The transformation temperature increased by at least $50^{\circ} \mathrm{C}$ for blanket $\mathrm{Ti}$ films, from $\approx 720^{\circ} \mathrm{C}$ to over $770^{\circ} \mathrm{C}$, when the film thickness decreased from 60 to $25 \mathrm{~nm}$. The effect of ramp rate on the transformation temperature was strongly affected by the initial film thickness. Varying the ramp rate caused no change in the transformation temperature for the $60 \mathrm{~nm}$ blanket Ti films. For blanket films of 25 or $40 \mathrm{~nm}$, however, increasing the ramp rate from 7 to $180^{\circ} \mathrm{C} / \mathrm{s}$ decreased the transformation temperature by $15^{\circ} \mathrm{C}$. Studies of patterned lines indicate that sheet 
resistance of narrow lines is also reduced by increased ramp rates for both $\mathrm{Ti}$ and $\mathrm{Ti}(\mathrm{Ta})$ films, especially as the linewidths decrease below $0.4 \mu \mathrm{m}$. This improvement is particularly pronounced for the $25 \mathrm{~nm} \mathrm{Ti(Ta)} \mathrm{film,} \mathrm{which} \mathrm{exhibited} \mathrm{virtually} \mathrm{no} \mathrm{linewidth}$ effect to below $0.3 \mu \mathrm{m}$ after being annealed with a $75^{\circ} \mathrm{C} / \mathrm{s} \mathrm{ramp} \mathrm{rate.} \mathrm{This} \mathrm{result} \mathrm{may} \mathrm{be} \mathrm{of}$ significant technological importance as critical dimensions for semiconductor devices continue to decrease.

The authors would like to thank the personnel at Sandia's Microelectronics Development Laboratory (MDL) for wafer processing. Pat Shea produced SEM micrographs for this work. Sandia is a multiprogram laboratory operated by Sandia Corporation, a Lockheed Martin Company, for the United States Department of Energy under Contract DE-AC0494AL85000. 


\section{References}

${ }^{1}$ Q.Z. Hong, J.A. Kittl, and M.S. Rodder, in Advanced Metallization for ULSI Applications in 1995, edited by Russell C. Ellwanger and Shi-Qing Wang (Materials Research Society, Pittsburgh, PA, 1996) pp. 431-438.

${ }^{2}$ E.G. Colgan, J.P. Gambino, and Q.Z. Hong, Mater. Sci. and Engr. R16, 2, 43 (1996).

${ }^{3}$ E. Ganin, S. Wind, P. Ronsheim, A. Yapsir, K. Barmak, J. Bucchignano, and R. Assenza, in Materials Research Society Symposium Proceedings Volume 303, Rapid Thermal and Integrated Processing II, edited by Jeffrey C. Gelpey, J. Kiefer Elliott, Jimmie J. Wortman, and Atul Ajmera (Materials Research Society, Pittsburgh, PA) p. 109 (1993).

4 L.A. Clevenger, R.A. Roy, C. Cabral, Jr., K.L. Saenger, S. Brauer, G. Morales, K.F. Ludwig, Jr., G. Gifford, J. Bucchignano, J. Jordan-Sweet, P. DeHaven, and G.B. Stephenson, J. Mater. Res. 10, 2355 (1995).

${ }^{5}$ C. Cabral, Jr., L.A. Clevenger, J.M.E. Harper, F.M. d'Heurle, R.A. Roy, C. Lavoie, K.L. Saenger, G.L. Miles, R.W. Mann, and J.S. Nakos, in Advanced Metallization and Interconnect Systems for ULSI Applications in 1997, edited by Robin Cheung, Jeffrey Klein, Kazuo Tsubouchi, Masanori Murakami, and Nobuyoshi Kobayashi (Materials Research Society, Warrendale, PA, 1998) p. 557.

${ }^{6}$ Z. Ma and L.H. Allen, Phys. Rev. B 49, 13501 (1994).

${ }^{7}$ R.W. Mann, G.L. Miles, T.A. Knotts, D.W. Rakowski, L.A. Clevenger, J.M.E. Harper, F.M. D’Heurle, and C. Cabral, Appl. Phys. Lett. 67, 3729 (1995).

${ }^{8}$ R.W. Mann, L.A. Clevenger and Q.Z. Hong, J. Appl. Phys. 73, 3566 (1993).

${ }^{9}$ Q. Xu and C. Hu, IEEE Trans. Electron Devices 45, 2002 (1998).

${ }^{10}$ Z. Ma, L.H. Allen, and D.D.J. Allman, Thin Solid Films 253, 451 (1994).

${ }^{11}$ C. Cabral, Jr., L.A. Clevenger, J.M.E. Harper, F.M. d'Heurle, R.A. Roy, K.L. Saenger, G.L. Miles, R.W. Mann, J. Mater. Res. 12, 304 (1997).

${ }^{12}$ H.J.W. van Houtum, I.J.M.M. Raaijmakers, and T.J.M. Menting, J. Appl. Phys. 61, 3116 (1987). 
${ }^{13}$ C. Cabral, Jr., L.A. Clevenger, J.M.E. Harper, F.M. d'Heurle, R.A. Roy, C. Lavoie, K.L. Saenger, G.L. Miles, R.W. Mann, and J.S. Nakos, Appl. Phys. Lett. 71, 3531, (1997).

${ }^{14}$ C.C.D. Tan, L. Lu, A. See, S.Y. Chen, L.H. Chua, K.L.T. Chan and L. Chan, presented at the $1^{\text {st }}$ International Conference on Advanced Materials and Processes for Microelectronics, San Jose, CA, March15-19, 1999.

${ }^{15}$ X.W. Lin and D. Promanik, in Materials Research Society Symposium Proceedings Volume 429, Rapid Thermal and Integrated Processing V, edited by J.C. Gelpey, M.C. Ozturk, R.P.S. Thakur, A.T. Fiory, and F. Roozeboom, (Materials Research Society, Pittsburgh, PA) p. 181 (1996).

${ }^{16}$ I. De Wolf, D.J. Howard, A. Lauwers, K. Maex, and H.E. Maes, Appl. Phys. Lett. 70, 2262 (1997).

17 H.J.W. van Houtum and I.J.M.M. Raaijmakers, in Materials Research Society Symposium Proceedings Volume 54, Thin Films - Interfaces and Phenomena, edited by R.J. Nemanich, P.S. Ho, and S.S. Lau (Materials Research Society, Pittsburgh, PA) p. 37 (1986).

${ }^{18}$ S.P. Murarka, Silicides for VLSI Applications, (Academic Press, Inc., New York, 1983) Chapter 4. 


\section{Figure Captions}

Figure 1. Sheet resistance as a function of RTP temperature for 25,40 , and $60 \mathrm{~nm}$ Ti films on poly-Si. These samples were processed with a ramp rate of $70^{\circ} \mathrm{C} / \mathrm{s} . \mathrm{T}_{\mathrm{TR}}$ is the temperature where linear fits to the sheet resistance in the transition region and the C54 region intersect.

Figure 2. Sheet resistance as a function of RTP temperature and ramp rate for $60 \mathrm{~nm}$ and $25 \mathrm{~nm}$ blanket Ti films on poly-Si. The $70^{\circ} \mathrm{C} / \mathrm{s}$ data has been omitted for clarity. It is obvious that the ramp rate affects $T_{T R}$ of the $25 \mathrm{~nm}$ Ti film but not $T_{T R}$ of the $60 \mathrm{~nm}$ film.

Figure 3. Transformation temperature, $\mathrm{T}_{\mathrm{TR}}$, as a function of nominal, as-deposited, Ti film thickness. Although the transformation temperature always increases with reduced film thickness, increasing the RTP ramp rate minimizes this effect.

Figure 4. Sheet resistance versus patterned linewidth of a $40 \mathrm{~nm}$, as-deposited, Ti film after processing at various ramp rates. The error bars indicate the minimum and maximum values of the measured data. It is obvious that the linewidth effect is monotonically reduced by increasing the ramp rate.

Figure 5. Sheet resistance versus patterned linewidth of a $25 \mathrm{~nm}$, as-deposited, $\operatorname{Ti}(\approx 4$ at. $\%$ Ta) film after processing at various ramp rates. The error bars indicate the minimum and maximum values of the measured data. The linewidth effect is virtually eliminated by increasing the ramp rate to $75^{\circ} \mathrm{C} / \mathrm{s}$. 


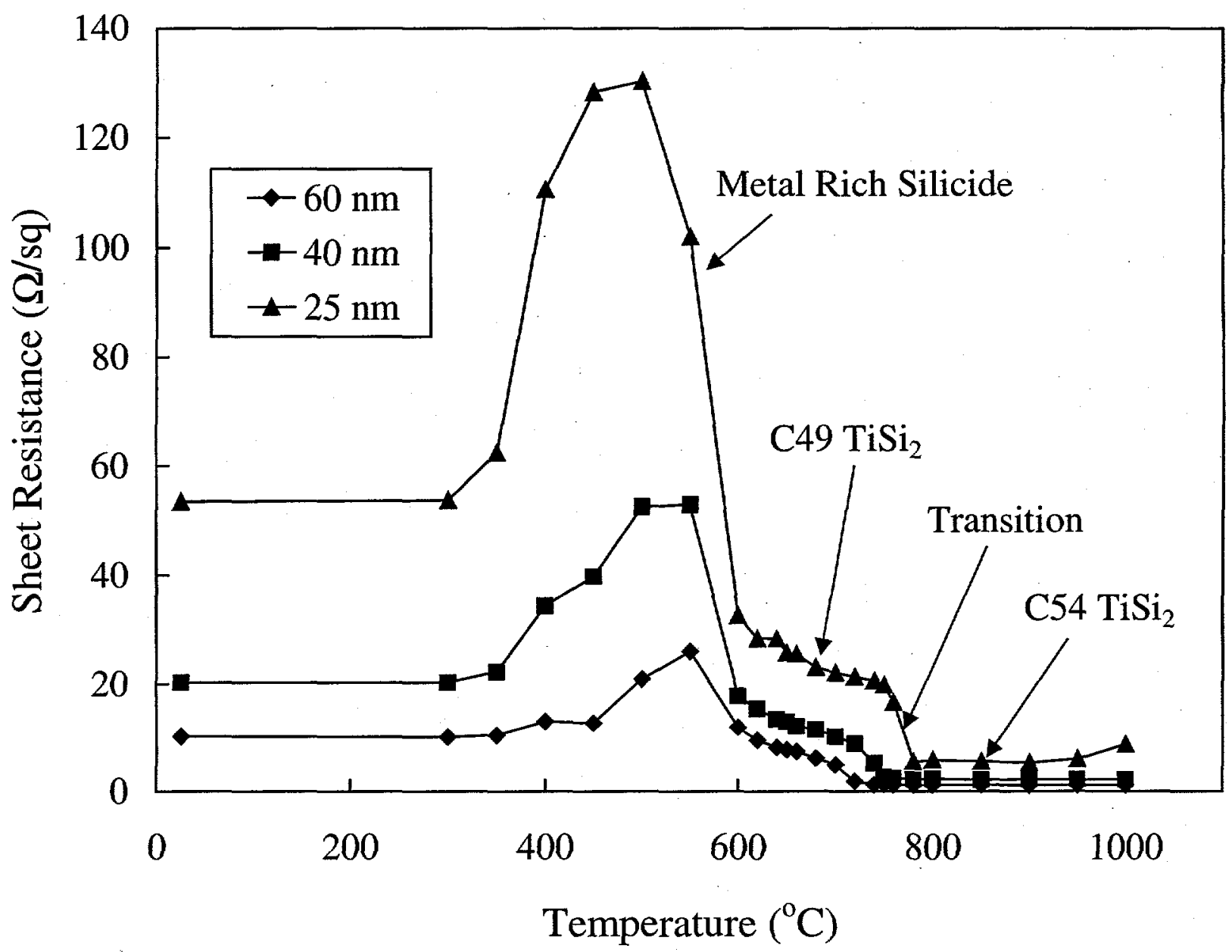

Figure 1. Sheet resistance as a function of RTP temperature for 25,40 , and $60 \mathrm{~nm}$ Ti films on $\mathrm{Si}$. These samples were processed with a ramp rate of $70^{\circ} \mathrm{C} / \mathrm{s}$. $\mathrm{T}_{\mathrm{TR}}$ is the temperature where linear fits to the sheet resistance in the transition region and the $\mathrm{C} 54$ region intersect. 


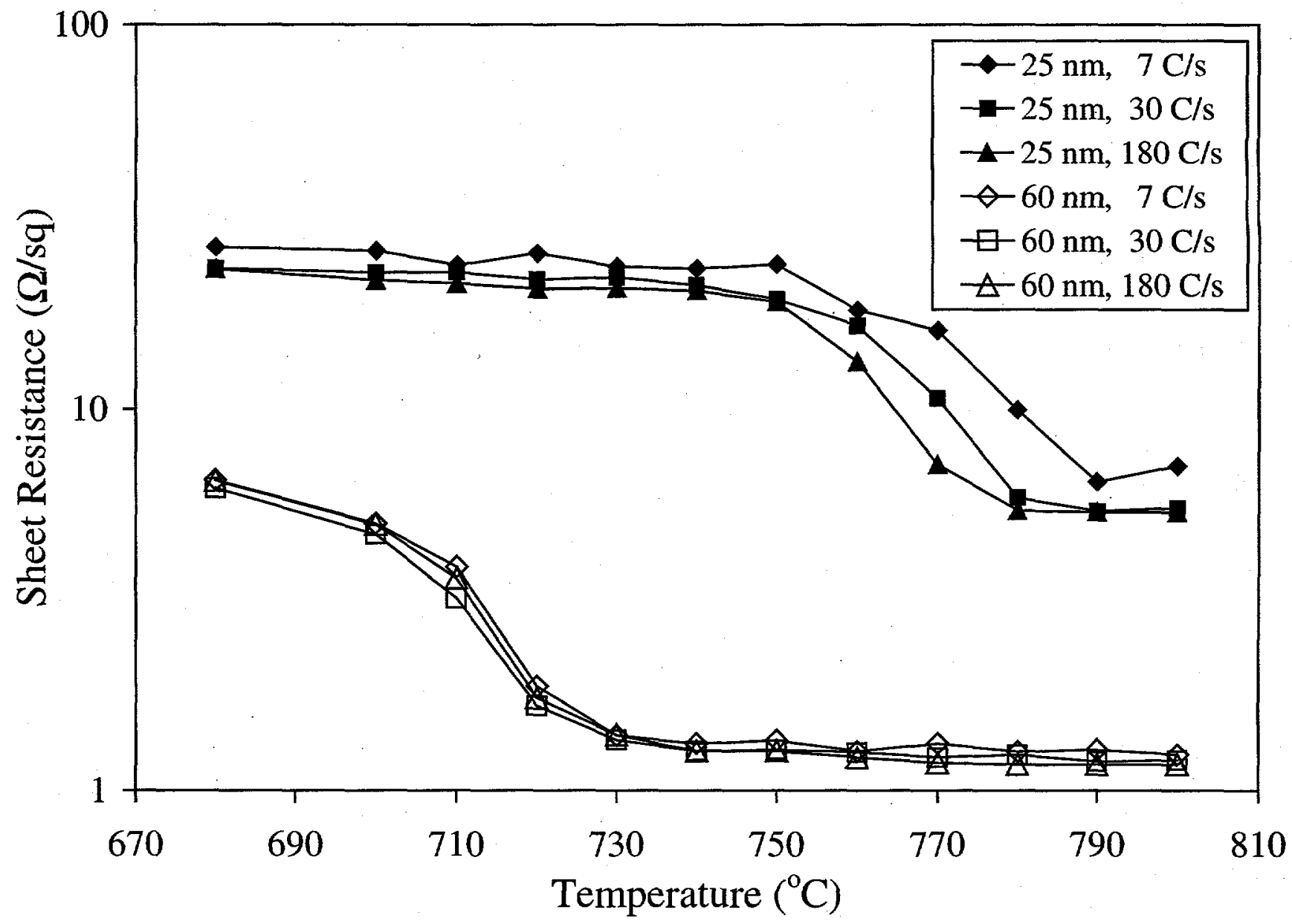

Figure 2. Sheet resistance as a function of RTP temperature and ramp rate for $60 \mathrm{~nm}$ and $25 \mathrm{~nm}$ blanket Ti films on Si. The $70^{\circ} \mathrm{C} / \mathrm{s}$ data has been omitted for clarity. It is obvious that the ramp rate affects $T_{T R}$ of the $25 \mathrm{~nm}$ Ti film but not $T_{\mathrm{TR}}$ of the $60 \mathrm{~nm}$ film. 


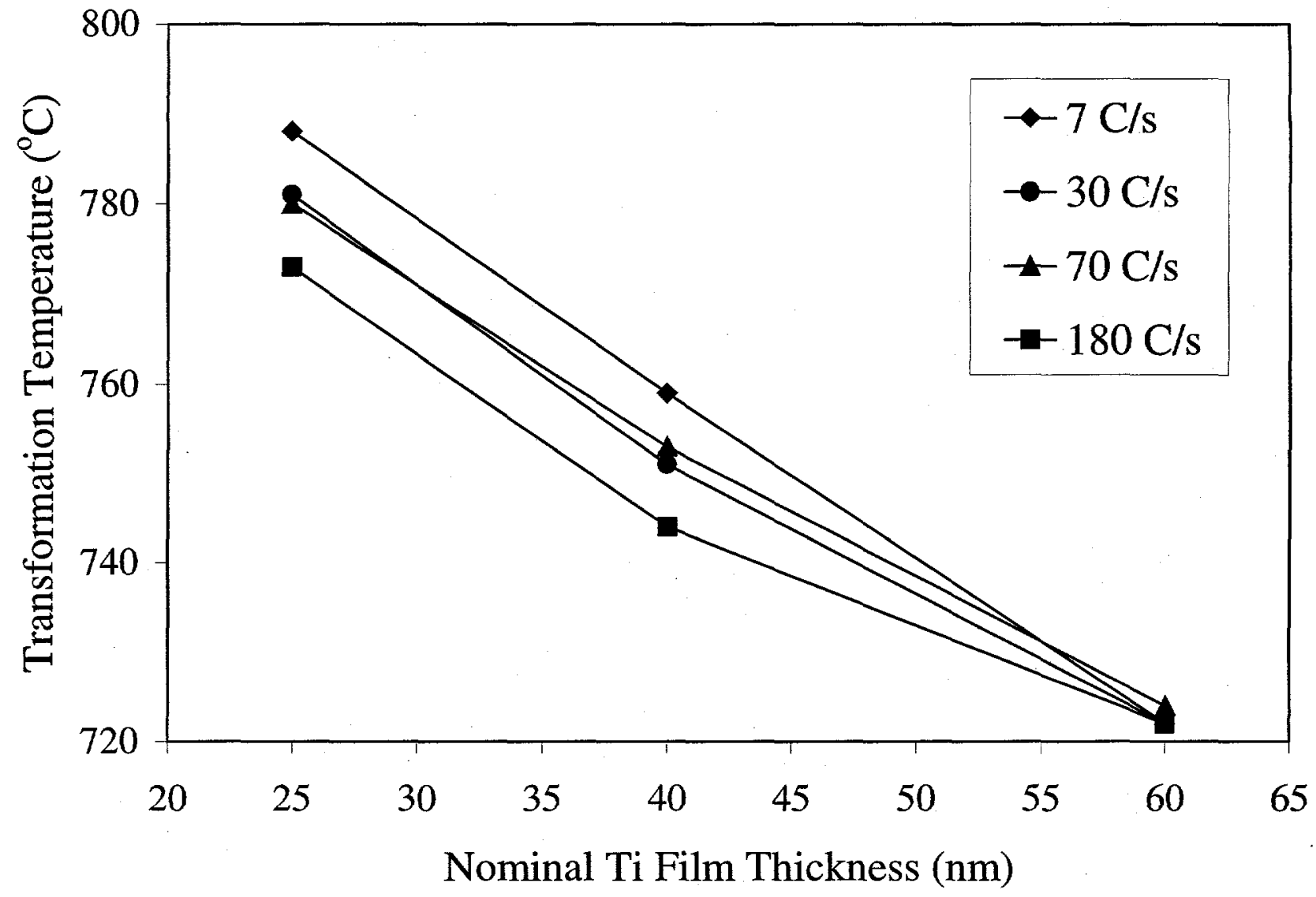

Figure 3. Transformation temperature, $T_{\mathrm{TR}}$, as a function of nominal, as-deposited, Ti film thickness. Although the transformation temperature always increases with reduced film thickness, increasing the RTP ramp rate minimizes this effect. 


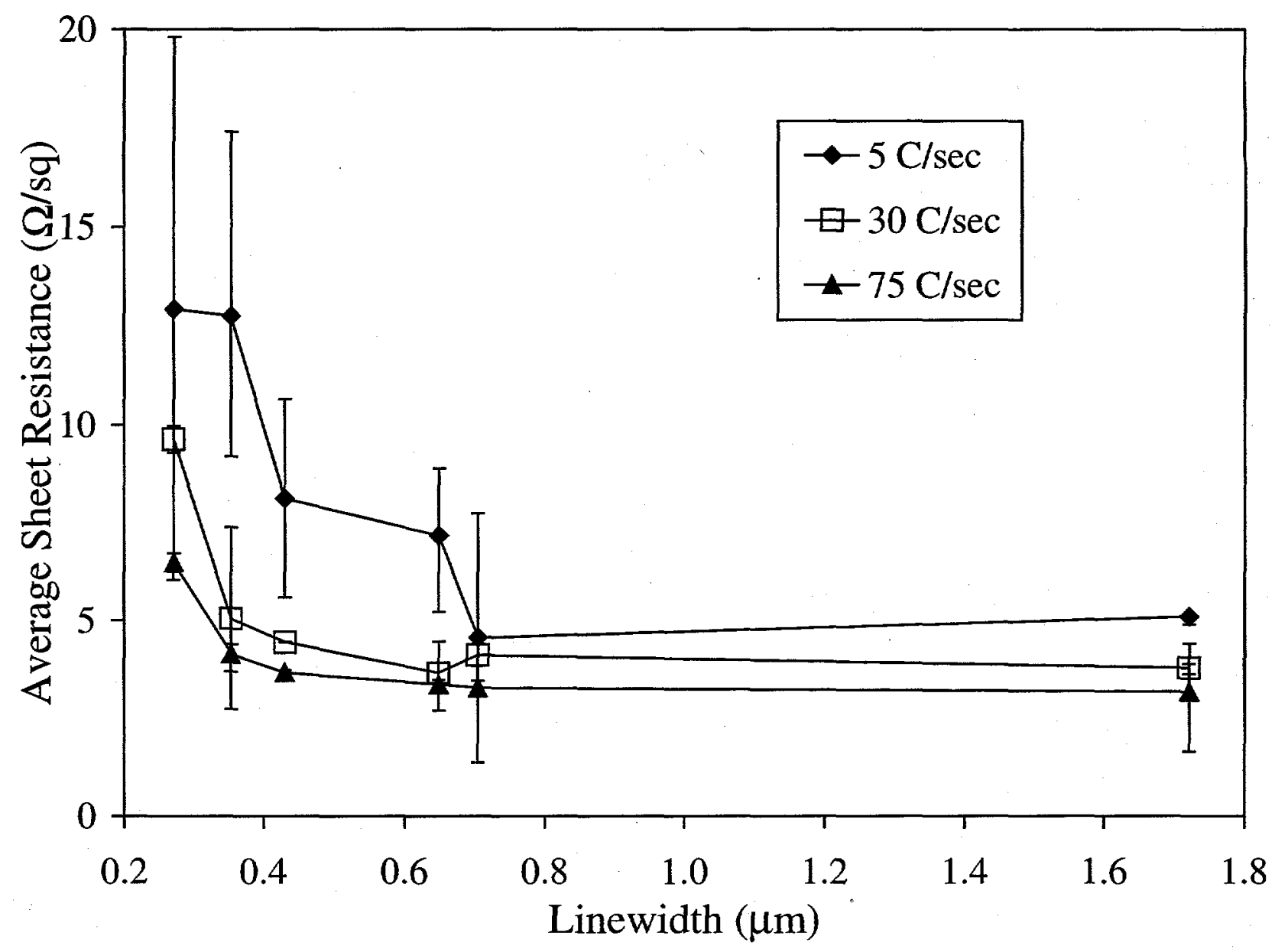

Figure 4. Sheet resistance versus patterned linewidth of a $40 \mathrm{~nm}$, as-deposited, Ti film after processing at various ramp rates. The error bars indicate the minimum and maximum values of the measured data. It is obvious that the linewidth effect is monotonically reduced by increasing the ramp rate. 


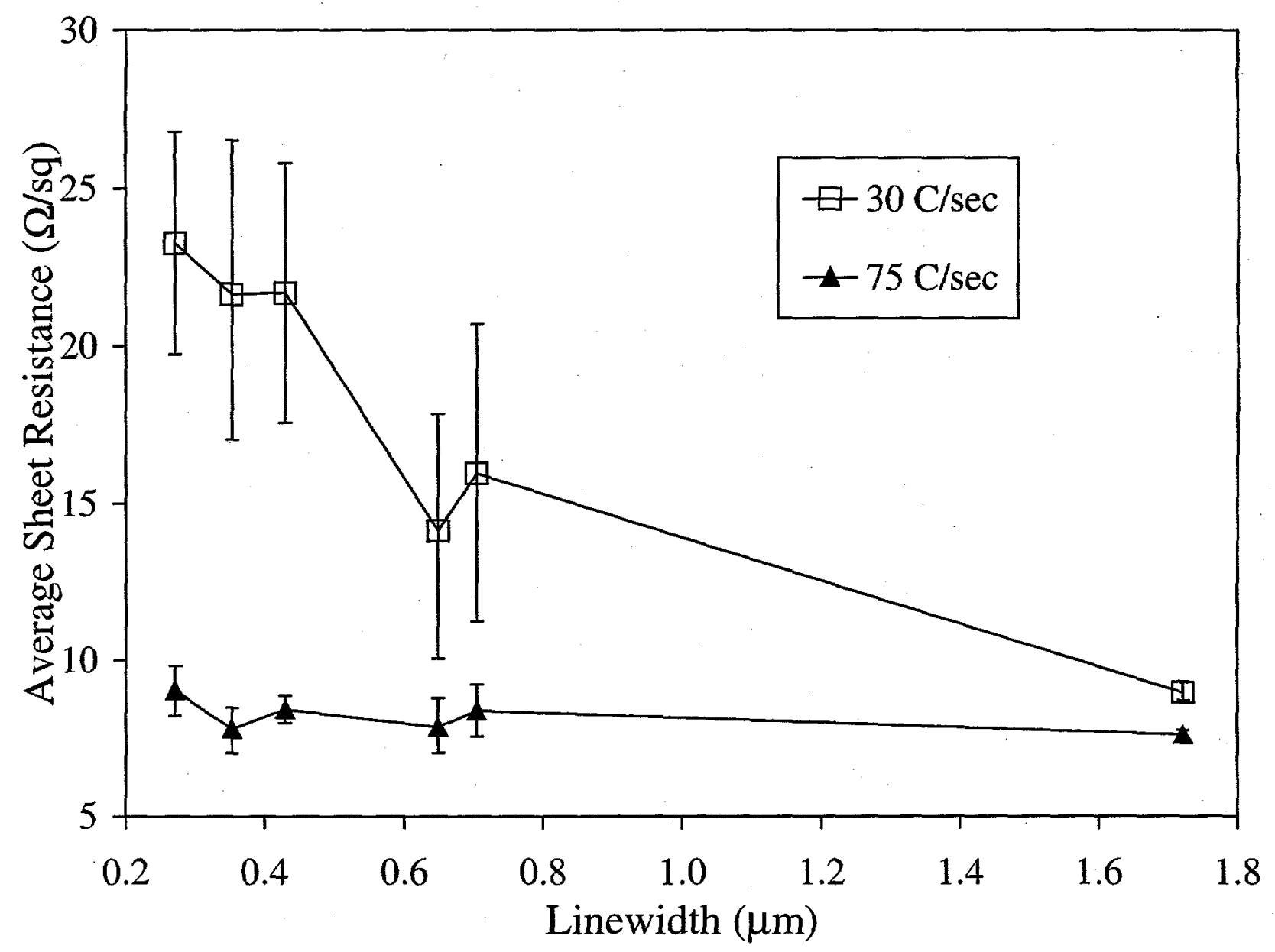

Figure 5. Sheet resistance versus patterned linewidth of a $25 \mathrm{~nm}$, as-deposited, $\mathrm{Ti}(\approx 4$ at. $\%$ Ta) film after processing at various ramp rates. The error bars indicate the minimum and maximum values of the measured data. The linewidth effect is virtually eliminated by increasing the ramp rate to $75^{\circ} \mathrm{C} / \mathrm{s}$. 